\title{
To name those lost: assessing extinction likelihood in the Australian vascular flora
}

\author{
J.L. Silcock, A.R. Field, N.G. Walsh and R.J. Fensham
}

\begin{abstract}
Extinction is a profound biological event, yet despite its finality it can be difficult to verify and many frameworks have been proposed to define formally that extinction has occurred. For most taxonomic groups and regions there is no reliable list of species considered to be probably or possibly extinct. The record of plant extinctions in Australia is no exception, characterized by high turn-over within lists, low transparency of attribution and lack of consistency between jurisdictions. This makes it impossible to evaluate how many plant taxa have become extinct in Australia. We present an ecological framework for assessing the likelihood of plant extinctions, based on taxonomic soundness, degree of habitat modification, detectability and search effort, underpinned by the best available expert knowledge. We show that, in sharp contrast to both the fate of the Australian fauna and prevailing assumptions, only 12 of 71 plant taxa currently listed as or assumed to be extinct are considered probably extinct, and a further 21 possibly extinct. Twenty taxa listed as or assumed to be extinct have dubious taxonomy or occurrence in Australia, and the remaining 18 taxa are considered possibly extant and further surveys are required to ascertain their status. The list of probably and possibly extinct plants is dwarfed by the number thought extinct but rediscovered since 1980 . Our method can be used for vascular floras in other regions characterized by well-documented and curated floras and high levels of expert knowledge, and provides a transparent platform for assessing changes in the status of biodiversity.
\end{abstract}

Keywords Australia, conservation assessment, extinction, flora, taxonomy, threatened species, surveys

Supplementary material for this article is available at https://doi.org/10.1017/So030605318001357

J.L. SILCOCK (Corresponding author) and R.J. FenSHAM ${ }^{*}$ Centre for Biodiversity and Conservation Science, National Environmental Science ProgramThreatened Species Recovery Hub, University of Queensland, St Lucia, 4072, Australia. E-mail j.silcock@uq.edu.au

A.R. FIELD* Australian Tropical Herbarium, James Cook University, Cairns, Australia

N.G. WALSH Royal Botanic Gardens Victoria, Birdwood Avenue, Melbourne, Australia

${ }^{*}$ Also at: Department of Environment and Science, Queensland Herbarium, Brisbane Botanic Gardens, Toowong, Australia

Received 23 July 2018. Revision requested 13 September 2018.

Accepted 30 October 2018. First published online 29 August 2019.

\section{Introduction}

xtinction is the inevitable end-point for all lifeforms (Koopowitz \& Kaye, 1990; Purvis et al., 2000), but the present rate of extinctions globally is estimated to be one thousand times the natural or background rate as a result of anthropogenic pressures on habitats and species (Barnosky et al., 2011; Pimm et al., 2014). Ignoring unproven re-creations, extinction of a species is irreversible and has biological, evolutionary and emotional consequences (Koopowitz \& Kaye, 1990; Ryan, 2009; Collen et al., 2010). With every global extinction, a unique evolutionary history is lost and the web of life irrevocably altered and diminished.

Yet despite the finality and magnitude of extinction, the actual event can be difficult to verify. Biology is replete with instances of so-called Romeo errors, in which species are declared or presumed extinct only to be rediscovered (Collar, 1998). Prominent recent examples include the ivory-billed woodpecker Campophilus principalis of the Big Woods of Arkansas (Fitzpatrick et al., 2005) and the enigmatic night parrot Pezeropus occidentalis of the Australian desert (Dooley, 2013). There have also been quieter rediscoveries amongst plants (Scott \& Yeoh, 1995; Wapstra et al., 2006; de Lírio et al., 2017; Sochor et al., 2018) and invertebrates (Bonham, 1997; Byk et al., 2018), and species whose continued existence remains the subject of intense debate, sometimes entering the realm of mythology, as for the Tasmanian tiger Thylacinus cynocephalus (Bailey, 2013).

The problem of verifying extinctions is a vexed issue for policy makers and scientists. IUCN guidelines state a species should be considered extinct when 'there is no reasonable doubt that the last individual has died' and that this is reliant on 'exhaustive surveys in known and/or expected habitat, at appropriate times...throughout its historic range' (IUCN, 2012). It has been argued that the IUCN criteria may not be an appropriate onus of proof when the aim is to assess extinctions accurately and consistently, and will severely underestimate extinctions (Butchart et al., 2006; Mace et al., 2008). In response to these concerns, the latest Red List Guidelines have an additional tag of 'Critically Endangered (Possibly Extinct)' for taxa 'that are, on the balance of evidence, likely to be extinct, but for which there is a small chance that they may be extant' (IUCN Standards and Petitions Subcommittee, 2017, p. 79). These taxa should not be listed as Extinct until adequate surveys have been completed and unconfirmed reports investigated. 
Statistical methods have also been developed for inferring extinction based on collection records and survey effort (Reed, 1996; Solow, 2005; Collen et al., 2010). These tend to be based on the distribution of sightings or collections through time, which can be used to calculate the expected rate of sightings if a species were extant. Although these formulae partially account for factors such as species abundance and detectability, they cannot account for life history traits (such as dormant or cryptic stages) and the potential complexity of a species' ecology, particularly when it is poorly known. Moreover, they rely on an adequate sample size (typically considered to be $>5$ records; Collen et al., 2010) and can seldom be applied to species with only one or two records, which is the case for many plants that are presumed extinct. Recent methodologies to estimate extinction probability have incorporated the timing and degree of threat, and a taxon's susceptibility (Keith et al., 2017), and record reliability and survey data (Thompson et al., 2017).

Listing of a species as Extinct has significant conservation implications for allocation of resources and environmental reporting (Keith \& Burgman, 2004). Thus it is important that lists of presumed and possibly extinct species are as accurate and transparent as possible. It has been estimated that Australia accounts for almost $20 \%$ of the world's flora that has been recently categorized as Extinct (Briggs \& Leigh, 1996), a fact that is usually explained by the continent's long isolation, high floristic endemism, and rapid and severe recent land-use changes (Lindenmayer, 2007; Nipperess, 2015). However, lists of Australia's extinct plants are characterized by high turn-over, low transparency of attribution and lack of consistency between jurisdictions (Keith \& Burgman, 2004). The first assessment in Australia defined Presumed Extinct species as not found despite thorough searching or not collected for at least 50 years, and formerly known from areas now well-settled, and listed 78 species that met those criteria (Leigh et al., 1981). Between 1984 and 2004, 115 taxa were added to the list of extinct Australian plants, mostly as a result of new evaluations, and 167 were deleted, mostly as a result of rediscoveries, but also because of taxonomic changes or corrections (Keith \& Burgman, 2004). This high turnover has continued, with numerous species discussed by Keith \& Burgman (2004) either rediscovered or synonymized, and numerous new species being added to national and state lists. The number of plant taxa that are actually likely to have become extinct in Australia is currently unknown, and without clearly defined criteria the issue will continue to be a point of confusion for plant conservation.

We present a transparent and uniform ecological framework for assessing plant extinctions, underpinned by expert knowledge of species and habitats. We provide an estimate of the current number of plant extinctions in Australia since 1788 and present a revised list of probably and possibly extinct species. This method can be used for vascular floras in other regions characterized by well-documented and curated floras and high levels of expert knowledge, and provides a coherent platform for assessing changes in the status of biodiversity.

\section{Methods}

We compiled a spreadsheet of taxa listed as Extinct according to the national Environment Protection and Biodiversity Conservation Act 1999 and lists of threatened species from individual states and territories. We also added unlisted taxa that are considered by experts, or noted in taxonomic treatments or state censuses, to be potentially or probably extinct. Taxa that are considered extinct in the wild but persist in translocated populations were included. Taxa that are not currently known from any living plants but are known to be extant in the soil seedbank or are considered extinct in one jurisdiction but still occur elsewhere in Australia were not included. Subspecies were included, but varieties, generally considered to be of lower taxonomic status, forms and hybrids are not considered here. We acknowledge that the distinction between subspecies and variety is unevenly applied by taxonomists, but have adopted this approach to filter out at least some trivial taxa. A separate list of taxa that have formerly been presumed to be globally extinct under national and/or state legislation was also compiled, to shed light on relevant factors behind extinction likelihood and assessment. Taxa listed as Extinct but that have been recently rediscovered were included.

For each taxon, data were compiled from Australian Virtual Herbarium records (CHAH, 2016), Conservation and Listing Advice, Recovery Plans, peer-reviewed literature, the assessments of Leigh et al. (1984) and Briggs \& Leigh (1996), and consultation with experts with field knowledge of species and habitats. Variables included the last date collected, survey effort and adequacy (Thompson et al., 2017), degree of habitat modification, intensity and extent of threats (Keith et al., 2017), detectability and life history of the species, and any taxonomic issues (Table 1). Taxa for which expert opinion or examination of specimens indicated they are morphologically close to co-occurring taxa and may not be taxonomically distinct were removed from further assessment, as were those whose occurrence in Australia is considered dubious. Species that also occur outside Australia were retained, but collecting dates and habitat notes relate only to Australian records.

To place some transparent and simple criteria around assignation of extinction likelihood, we devised a key containing relevant factors from Table 1. Through this key, each of the taxa currently listed as Extinct in Australia was assigned an extinction confidence/likelihood: (1) Almost 
TABLE 1 Data compiled for each presumed extinct taxon in the Australian vascular flora.

\begin{tabular}{|c|c|}
\hline Data field & Description \\
\hline Conservation status & Environment Protection and Biodiversity Conservation Act \& state listing \\
\hline Taxonomy & $\begin{array}{l}\text { Any taxonomic issues noted, including notes on closely-related taxa; where there is considerable taxo- } \\
\text { nomic uncertainty, the taxon was removed from further consideration }\end{array}$ \\
\hline Occurrence reliability & $\begin{array}{l}\text { Expert assessment about whether taxa actually occurred in Australia; where occurrence is apparently } \\
\text { because of mislabelled specimens, or otherwise considered dubious, taxa were removed from further } \\
\text { consideration }\end{array}$ \\
\hline State \& bioregion(s) & Biogeographical regions as per Thackway \& Cresswell (1995) \\
\hline Habitat summary & $\begin{array}{l}\text { Best available information on habitat from specimen label; where this was not available, expert opinion on } \\
\text { most likely habitat is given where possible }\end{array}$ \\
\hline Last date collected & $\begin{array}{l}\text { Year of last collection or reliable observation; where this was not available, an estimate is given based on } \\
\text { when the collector was active in the area of collection }\end{array}$ \\
\hline Lifeform & Tree, shrub, perennial grass, annual grass, perennial herb, annual herb, orchid, fern \\
\hline $\begin{array}{l}\text { Number of collections \& } \\
\text { populations }\end{array}$ & $\begin{array}{l}\text { Number of times collected (collections by the same collector on the same day but in different herbaria are } \\
\text { classed as a single record; collections made at the same place by different collectors or by the same collector } \\
\text { at different times are treated as separate collections) }\end{array}$ \\
\hline Location precision & $\begin{array}{l}\text { Precision of most accurate record, in } \mathrm{km}^{2} \text {; calculated by drawing a minimum convex polygon around the } \\
\text { area within which the location description indicates the record lies. If the exact location of the record is } \\
\text { available as GPS-determined coordinates, the precision is } 0.1 \mathrm{~km} \text {. We considered } 5 \mathrm{~km}^{2} \text { a reasonable area } \\
\text { that could be searched to confidently rule out the taxon being present at the time of survey, based on } \\
\text { extensive field experience of the authors }\end{array}$ \\
\hline Abundance information & If recorded \\
\hline Detectability & Low, moderate or high, with cryptic life history stages, disturbance response and other factors noted \\
\hline Life history knowledge & $\begin{array}{l}\text { Will inform best times for survey, possible reasons for extinction, microhabitats or land management } \\
\text { regimes where most likely to be found }\end{array}$ \\
\hline Targeted surveys & Thoroughness \& time period of searches \\
\hline $\begin{array}{l}\% \text { of suitable remaining } \\
\text { habitat searched }\end{array}$ & Estimated from vegetation mapping, satellite imagery \& expert opinion \\
\hline $\begin{array}{l}\text { Degree of habitat } \\
\text { modification }\end{array}$ & $\begin{array}{l}\text { High ( }<30 \% \text { of vegetation type remains as remnant vegetation); moderate (substantial remnants remain } \\
\text { but many highly modified); or low ( }>70 \% \text { of vegetation type remains as remnant vegetation, \& is con- } \\
\text { sidered to still provide suitable habitat for taxon) }\end{array}$ \\
\hline $\begin{array}{l}\text { Threat/potential cause of } \\
\text { extinction }\end{array}$ & $\begin{array}{l}\text { Threats that may have driven taxon to extinction; intensity \& extent of threat, \& susceptibility of taxon } \\
\text { assessed }\end{array}$ \\
\hline Extinction likelihood & Almost certainly extinct; probably extinct; possibly extinct; possibly extant (see key in Methods) \\
\hline Notes & Relevant to taxon biology, life history or extinction assessment \\
\hline Source(s) & Relevant literature \& expert botanist/s interviewed \\
\hline
\end{tabular}

certainly extinct, (2) Probably extinct, (3) Possibly extinct (on the balance of evidence, must be considered extinct but requires further surveys where possible to confirm its status), and (4) Possibly extant (surveys undertaken thus far have not been sufficient to consider the taxon extinct).

In the key, a taxon can be found at any stage from step 5. This possibility is not included in the key, as it will of course lead to removal of the species from any extinction considerations. It is also possible to locate the target species with searching, but for taxonomic uncertainty to preclude definitive identification; this will mean returning to step 1. The amount of survey effort before assuming extinction has occurred increases with lack of spatial precision, low habitat modification/threat and cryptic lifeform stages/low detectability. It is impossible to get more certain than probably extinct unless precision of at least one record is $<5 \mathrm{~km}^{2}$, or $>90 \%$ or remaining habitat is surveyed, and detectability is high or surveys span multiple seasons and years. The cut-off for record accuracy is the approximate amount of habitat that can be confidently searched by a botanist in one day. This will vary between habitats and lifeforms, but $5 \mathrm{~km}^{2}$ is considered reasonable based on $>2,000$ hours of our own searching for rare plants. The 90, 70 and 50\% cut-offs for area of suitable habitat searched are intended as reasonable guiding estimates. Assessments of the level of understanding of a taxon's life history and optimum survey times relies upon expert opinion. 


\section{Key for assessing extinction likelihood in vascular floras}

The number of taxa from the 71 presumed extinct Australian species is indicated at each couplet.

1. Subject to taxonomic uncertainty . . . . . . . . . . . . . . . . . Revise taxonomy $(\mathrm{n}=13)$

1a. Reliable taxon or sufficient certainty to warrant further searching. . . . . . . . . . . . . . . . 2

2. Suspected identification or location error, and taxon unlikely to occur in Australia .

. . . . . . . . . . . . . . . . Discard unless further information available $(\mathrm{n}=7)$

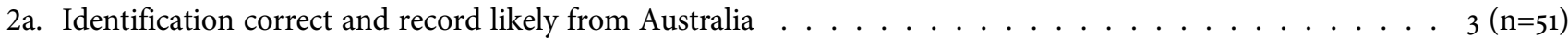

3. At least one collection record able to be located to within $5 \mathrm{~km}^{2} \ldots \ldots \ldots \ldots \ldots$. . . . . . . . . . . .

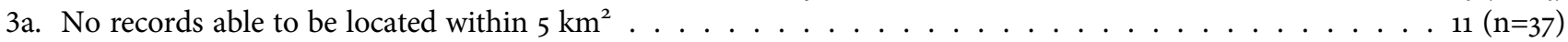

4. Long-lived species, no cryptic lifeform stages . . . . . . . . . . . . . . . . . . . . . 5 (n=5)

4a. Ephemeral species or geophyte, cryptic or dormant lifeform stage/s . . . . . . . . . . . . . . . . $8(\mathrm{n}=9)$

5. Habitat highly modified or destroyed AND/OR well-known threatening process . . . . . . . . . . . $6(\mathrm{n}=3)$

5a. Habitat not or only lightly modified AND no well-defined threatening process . . . . . . . . . . . . $7(\mathrm{n}=2)$

6. Thorough searching at site/s and $>90 \%$ of potential habitat . . . . . . . . . Almost certainly extinct $(\mathrm{n}=2)$

6a. Thorough search effort at site/s and $>70 \%$ of potential habitat . . . . . . . . . . . . . Probably extinct $(\mathrm{n}=1)$

6b. Search effort less than $6 \mathrm{a} \ldots \ldots$. . . . . . . . . Possibly extinct; surveys needed to confirm $(\mathrm{n}=\mathrm{o})$

7. Thorough searching at site/s and $>70 \%$ of other potential habitat . . . . . . . . . . Probably extinct $(\mathrm{n}=0)$

7a. $<70 \%$ of site and suitable habitat effort at site/s . . . . . . . Possibly extinct; further surveys needed $(\mathrm{n}=2)$

8. At least moderate understanding of life history/optimum survey times (e.g. seasonal conditions/disturbance events likely

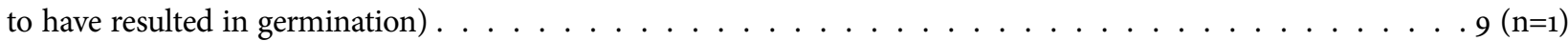

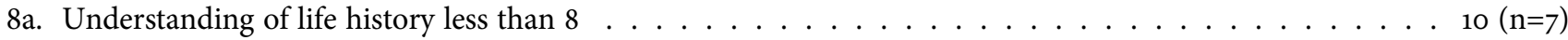

9. Thorough searching at site/s and $>70 \%$ of suitable habitat at more than one optimum time/s AND habitat highly disturbed OR threatening process operating . . . . . . . . . . . . . . . . . Probably extinct $(\mathrm{n}=2)$

9a. Thorough searching at site/s AND $>70 \%$ of suitable habitat at more than one optimum time/s; habitat not or lightly modified AND no well-defined threats . . . . . . . . . . . . . . . . . Possibly extinct $(\mathrm{n}=\mathrm{o})$

9b. Search effort less than $9 \mathrm{a} \ldots \ldots$. . . . . . . . . . . . . Possibly extant, surveys needed $(\mathrm{n}=\mathrm{\ldots})$

10. Site/s of historic collection $+>90 \%$ of other potential habitat searched across multiple seasons and conditions AND habitat highly modified . . . . . . . . . . . . . . . . . . Probably extinct $(n=3)$

10a. Site/s of historic collection $+50-90 \%$ of other potential habitat searched across multiple seasons and conditions AND habitat highly to moderately modified . . . . . . . . . . . . . . . . . Possibly extinct $(\mathrm{n}=3)$

10b. Site/s of historic collection not well-searched and/or $<50 \%$ of potential habitat searched across multiple seasons and conditions . . . . . . . . . . . Possibly extant; further surveys in various seasons needed $(n=1)$

11. Habitat not known from record labels; record precision $>100 \mathrm{~km}^{2} \ldots \ldots \ldots \ldots$. . . . . . 12 (n=4)

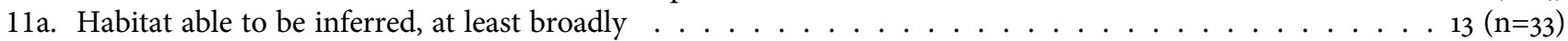

12. General area highly modified and well-surveyed . . . . . . . . . . . . . . . . Possibly extinct $(\mathrm{n}=4)$

12a. General area not highly modified and no major threats identified . . . . . . . . . . . . Possibly extant $(\mathrm{n}=\mathrm{o})$

13. Habitat highly modified AND/OR documented threatening process/es . . . . . . . . . . . . 14 $(\mathrm{n}=8)$

13a. Habitat not heavily modified, or at least large remnants remaining unaffected by major threatening processes . . .

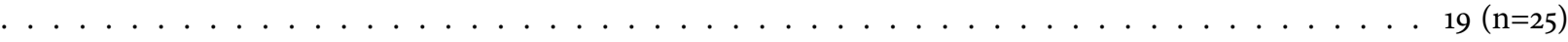

14. Long-lived species, no cryptic lifeform stages . . . . . . . . . . . . . . . . . . . . . . . 15 $(\mathrm{n}=4)$

14a. Ephemeral species or geophyte, cryptic or dormant lifeform stage/s . . . . . . . . . . . . . . $16(\mathrm{n}=4)$ 
15. $>90 \%$ of potential habitat searched . . . . . . . . . . . . . . . . . . . . Probably extinct $(\mathrm{n}=3)$

15b. $50-90 \%$ of potential habitat searched . . . . . . . . . . . Possibly extinct; further surveys needed (n=1)

15c. $<50 \%$ of potential habitat searched . . . . . . . . . . . Possibly extant; further surveys needed (n=o)

16. Good understanding of species, life history/optimum survey times . . . . . . . . . . . . . . . . . . 17 (n=o)

16a. Poor understanding of species, life history . . . . . . . . . . . . . . . . . . . . . . . . . . . 18 (n=4)

17. $>90 \%$ of potential habitat searched repeatedly at optimum times . . . . . . . . . . Probably extinct (n=o)

17a. 50-90\% of potential habitat searched at optimum times . . . . . . . . . . . . . . . . Possibly extinct (n=o)

17b. $<50 \%$ of potential habitat searched at optimum times . . . . . . . . . . . . . . . Possibly extant (n=o)

18. $>90 \%$ of potential habitat searched repeatedly in multiple seasons . . . . . . . . . . . Probably extinct (n=1)

18a. $>70 \%$ of potential habitat searched repeatedly in multiple seasons . . . . . . . . . . . . Possibly extinct (n=3)

18b. $<70 \%$ of potential habitat searched . . . . . . . Possibly extant; surveys in various seasons needed (n=o)

19. At least moderately detectable taxon with no cryptic lifeform stages . . . . . . . . . . . . . . . . 20 (n=16)

19a. Low detectability, complex disturbance response and/or cryptic lifeform stages . . . . . . . . . . . . . . 21 (n=9)

20. $>70 \%$ of potential habitat searched . . . . . . . . . . . . . . . . . . . Possibly extinct $(\mathrm{n}=5)$

20a. $<70 \%$ potential habitat searched . . . . . . . . . . . . Possibly extant; further surveys needed (n=12)

21. Good understanding of species life history/optimum survey times . . . . . . . . . . . . . . . . 22 (n=1)

21a. Poor understanding of species life history . . . . . . . . . . . . . . . . . . . . . . . . 23 (n=7)

22. $>70 \%$ of potential habitat searched repeatedly at suitable times . . . . . . . . . . . . Possibly extinct (n=o)

22a. $<70 \%$ of potential habitat searched repeatedly at suitable times . . . . . . . . . . . . . . . . . .

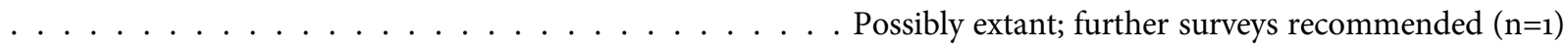

23. $>70 \%$ of potential habitat searched across numerous seasons . . . . . . . . . . . . . . Possibly extinct (n=4)

23a. $<70 \%$ of potential habitat searched . . . . Possibly extant; further surveys in various seasons recommended ( $\mathrm{n}=3$ )

TABLE 2 Presumed extinct taxa in the Australian vascular flora, and their extinction likelihood as assessed using the methodology described here. Taxa from different regions are separated by semi-colons.

\begin{tabular}{|c|c|}
\hline Extinction likelihood & Region and taxa \\
\hline $\begin{array}{l}\text { Almost certainly } \\
\text { extinct (in the wild) }\end{array}$ & Norfolk Island group: Streblorrhiza speciosa; Sydney: Allocasuarina portuensis \\
\hline Probably extinct & $\begin{array}{l}\text { South-west Western Australia: Acacia kingiana, Darwinia divisa, Picris compacta, Tetratheca fasciculata; Greater } \\
\text { Sydney: Deyeuxia appressa, Gentianella wingecarribiensis, Persoonia laxa; south-eastern South Australia: } \\
\text { Gentianella clelandii, Prasophyllum colemaniarum; Pacific Subtropical Islands: Solanum bauerianum }\end{array}$ \\
\hline Possibly extinct & $\begin{array}{l}\text { South-west Western Australia: Coleanthera virgata, Lepidium drummondii, Leptomeria dielsiana, Leucopogon } \\
\text { cryptanthus, Myriocephalus nudus, Picris wagenitzii, Ptilotus caespitulosus, Ptilotus sericostachyus subsp. roseus, } \\
\text { Scholtzia sp. Bickley (W.H. Loaring s.n. PERTH 06165184), Thomasia gardneri; north-eastern New South Wales: } \\
\text { Euphrasia ruptura, Homoranthus elusus, Indigofera efoliata; South-eastern Australia: Ozothamnus selaginoides, } \\
\text { Pomaderris sericea, Pultenaea maidenii, Prasophyllum sp. Majors Creek (Jones 11084), Senecio georgianus, } \\
\text { Senecio helichrysoides; Brigalow Belt, Queensland: Corchorus thozetii; Christmas Island: Peperomia rossii }\end{array}$ \\
\hline Possibly extant & $\begin{array}{l}\text { Brigalow Belt, Queensland: Amphibromus whitei, Calotis glabrescens; Coastal Queensland: Genoplesium sp. (Raby } \\
\text { Bay), Goodenia arenicola; Gulf Country, Queensland: Ptilotus senarius; Paspalum batianoffii, Persoonia prostrata; } \\
\text { Wet Tropics, Queensland: Embelia flueckigeri, Pseudodiphasium volubile, Marsdenia araujacea, Lastreopsis dis- } \\
\text { secta, Wendlandia psychotrioides; New England Tablelands, New South Wales: Leucopogon confertus; south-west } \\
\text { Western Australia: Conospermum caeruleum subsp. contortum; Greater Sydney/central New South Wales: } \\
\text { Grevillea divaricata, Olearia oliganthema, Pultenaea elusa; Tasmania: Senecio tasmanicus }\end{array}$ \\
\hline
\end{tabular}




\section{Results}

\section{Overview of presumed extinct plants}

Of the 71 Australian plant taxa currently listed as or presumed to be extinct, 13 (18\%) are considered to be taxonomically suspect (Supplementary Table 1). Nine of these are known only from the type specimen, which often comprises incomplete fragments, and the other four are known from 2-5 collections. Seven have not been collected for the past 100 years. All are very close morphologically to other co-occurring species, and belong in groups regarded as taxonomically ill-defined and difficult, for example Frankenia L., Hemigenia R.Br. and the Orchidaceae genera Caladenia, Diuris and Prasophyllum.

The occurrence in Australia of a further seven presumed extinct taxa, all ferns from the Wet Tropics of north-eastern Australia, is dubious (Supplementary Table 1). All are relatively widespread tropical ferns and their extinction in Australia would represent local extinctions, but their apparent occurrences in Australia represent highly disjunct, and sometimes biogeographically unlikely, populations. Three are known only from collections by Czech botanist Karel Domin in 1909, and two from Domin's published descriptions without specimens. There are large areas of intact rainforest habitat where they occurred and there has been extensive survey effort in these areas. Where specimens are available, they have been verified as being correctly identified, however a labelling error on this batch of specimens cannot be ruled out, as Domin also visited areas outside Australia on the same expedition where the ferns in question do occur.

There are 51 taxa with sound taxonomy and unambiguous occurrences in Australia that are currently considered extinct (Supplementary Table 2). Although experts consider them all reliable taxa, there has been some degree of taxonomic confusion with closely-related species in the past for 19, and hybrid origins of four cannot be discounted without further material. Eighteen of the 51 taxa are listed as Extinct under both the national Environment Protection and Biodiversity Conservation Act and state legislation, and a further 14 are listed only under state legislation. Fourteen are listed as either Critically Endangered, Endangered, Vulnerable or Priority Flora (Western Australia) under the Environment Protection and Biodiversity Conservation Act and/or state legislation, and five are unlisted, but recent publications, taxonomic treatments, state censuses and/or expert opinion consider them potentially extinct. Most families are represented by one or two taxa, but Asteraceae stands out with nine species and Fabaceae and Proteaceae with five and four, respectively. Western Australia has the highest number of presumed extinct taxa (16, all bar one from the south-west), followed by New South Wales (15) and Queensland (13). The
Northern Territory and Australian Capital Territory have no presumed extinct plants. Three presumed extinct taxa come from islands. Shrubs are the most represented life form, with 22 presumed extinct taxa, followed by mostly short-lived forbs (18).

All taxa presumed extinct seem to have been rare and/or restricted throughout their historic range, with 22 known from a single collection and all bar five known from $<5$ collections. Only three are known from $\geq 5$ populations. Twenty-four have not been collected in the last 100 years and 41 in the past 50 years. Those with more recent collections have been searched for repeatedly at sites where they formerly occurred and not found, or the habitat has been destroyed. At least 23 are regarded as difficult to detect, having tiny growth habits, cryptic life forms and/or complex seed bank or disturbance dynamics. More than half are known or strongly suspected to respond positively to disturbance.

\section{Assessing extinction likelihood}

Applying our key of ecological and survey factors, only two species are considered almost certainly extinct in the wild (although one persists in a translocated population), 10 are considered probably extinct and 21 possibly extinct (Table 2). The remaining 18 taxa are classified as possibly extant, primarily because of lack of adequate surveys to inform their status.

To be assigned to the almost certainly extinct category, a species must have a record with high locational precision $\left(<5 \mathrm{~km}^{2}\right)$, which has been searched at an appropriate time/s by expert botanists. A high proportion of other suitable habitat in the vicinity will also have been searched. There will usually, although not always, be a demonstrable threat from destruction or major modification of habitat. This condition was met for just two species, Allocasuarina portuensis, which is almost certainly extinct in the wild but persists as translocated plants at a number of locations (Office of Environment \& Heritage, 2017) and Streblorrhiza speciosa, a scrambling shrub known from the highly modified Phillip Island in the Norfolk group that has not been seen since 1830 despite targeted surveys (Schrire, 2007).

The 10 taxa considered probably extinct come from highly modified agricultural and urban areas with little remnant vegetation, including four from south-western Australia and three from the Greater Sydney area. All have at least one record that could be located to within $50 \mathrm{~km}^{2}$ (with the exception of Acacia kingiana, the record only being accurate to within $200 \mathrm{~km}^{2}$ but with a clear habitat description) and have had $>70 \%$ of remaining habitat searched $(>90 \%$ for seven taxa). Five are considered to have low detectability, and most probably respond to disturbance. Paradoxically, species with more recent records are more likely to be assessed as 
probably extinct, as these more recent records are known from precise localities, whereas older records often have very low precision, rendering targeted survey difficult.

Although records could be located within $5 \mathrm{~km}^{2}$ for only 14 taxa, habitat could be inferred, at least broadly, for all except four taxa (Supplementary Tables 1 \& 3). All four are James Drummond collections from south-western Western Australia, collected in the 1840s-1850s from an area that is now both heavily modified and well-surveyed botanically. Thus despite lack of location precision, three are assigned as possibly extinct. A further 10 Western Australian taxa were assessed as possibly extinct, as well as six from south-eastern Australia and three from the northeast of New South Wales (Table 2). Location precision and detectability vary, but nearly all have had at least $>70 \%$ of potential habitat searched (repeatedly for taxa with cryptic life forms stages and seasonal fluctuations in abundance). The habitat of seven is highly modified. Two species, the short-lived disturbance-responsive forb Corchorus thozetii from central Queensland and the shrub Pomaderris sericea from mountainous terrain in Victoria and New South Wales, have had $<70 \%$ of remaining potential habitat searched at appropriate times but are known from at least one accurate record that has been revisited without the species being relocated. In the case of the former, the site where it was collected in the 1990s has now been cropped, but other suitable habitat remains unsurveyed. The main reason for possibly extinct taxa not being assessed as probably extinct was that their habitats were not highly modified and there were no threats affecting the entire range of the species. This often occurred in concert with low detectability and/ or complex and poorly-understood disturbance dynamics.

The remaining 18 taxa assessed as possibly extant have had $<70 \%$ of their potential habitat searched, and in some cases much less, combined with large areas of remnant suitable habitat and few severe threats. The exception is Genoplesium sp. (Raby Bay), which would have been ranked as probably extinct as a result of the high level of habitat modification, until a possible collection of an infertile specimen in 2017 (Lui Weber, pers. comm., February 2018). Twelve of these taxa are known or strongly considered to be responsive to disturbance, with large temporal fluctuations further increasing the demands for repeated surveys to reliably infer extinction. Five are from the rainforests of north Queensland, and another five from the sub-coastal and coastal areas of Queensland.

\section{Formerly extinct plants}

More than 120 taxa previously presumed extinct (i.e. listed under state and/or federal legislation and/or Leigh et al. (1984) or Briggs \& Leigh (1996), or identified as such in published sources such as taxonomic treatments) have been rediscovered in Australia, mostly since the 1980 s (Supplementary Table 3). Over half of these (67) have been straightforward rediscoveries in the field, but 36 have involved rediscoveries of specimens collected decades earlier that had not been correctly identified at the time of their collection. In many cases, taxonomic revisions or apparent field rediscoveries trigger re-examination of collections. Conversely, specimen rediscoveries sometimes result in renewed targeted surveys, which in turn locate further populations. Only five of the 36 specimen rediscoveries have occurred in isolation from field rediscoveries. The remaining 24 taxa presumed extinct have been removed because of taxonomic revision revealing them as synonyms of more widespread taxa (in 19 cases), of hybrid origin or more widespread than previously thought as a result of revision of the species' concept. Seven of these taxa are still listed on extinct lists, including five under the Environment Protection and Biodiversity Conservation Act.

The average time that these rediscovered plant species have been apparently lost (excluding those with taxonomic issues) was 93 years, and 42 had not been seen for $>100$ years before they were rediscovered. Western Australia accounts for $>60 \%$ of rediscoveries $(n=74)$, with 21 from Queensland. One-third are known from highly modified habitats, a factor that contributed to their being considered extinct, but 40 are known from habitats that mostly remain in remnant condition, with few threats present. Fifty-six are shrubs, 41 annual or perennial forbs, nine grasses and sedges, and eight ground orchids. More than 50 were known from a single recognized collection prior to their rediscovery, while only six had been known from $>5$ collections. Over half of formerly presumed extinct plants are now known to be abundant or at least locally common, although $>45 \%$ of these respond to fire or other disturbance and thus exhibit large temporal fluctuations. Although 19 remain known from a single rediscovered population and are categorized as Endangered or Critically Endangered, 44 are now known from at least 10 populations. Eighty-two per cent of rediscoveries and specimen rediscoveries have occurred since 1980, with over half of these occurring in the 1990 os. There has been an average of one rediscovery per year over the past decade across Australia, the latest being the ferns Oreogrammitis leonardii and Hymenophyllum whitei, both collected for the first time in 70 years in 2018 on remote mountain tops in far north Queensland, and the shrub Acacia prismifolia, collected beside a busy highway in south-western Australia in 2018, having not been seen since 1933.

\section{Discussion}

The systematic assessment of extinction likelihood amongst the Australian vascular flora reveals that the true extinction 
toll is far less than previous assessments, in sharp contrast to the general perception that the number of identified extinctions languishes behind the true number that have occurred (Butchart et al., 2006; Collen et al., 2010). This is partly a result of the listing of many plant species that are now considered taxonomically dubious or that never occurred in Australia, and partly a result of the vastness and inaccessibility of some largely unmodified habitat types, the tiny proportion able to be feasibly surveyed, and the cryptic life form stages of many species (a response to Australia's variable climatic conditions). The history of rediscoveries and taxonomic changes reinforces the fact that taxonomic assessment and adequate surveys must precede any declarations of extinction, especially if large swathes of habitat are still intact and threatening processes cannot be identified.

Species with unresolved taxonomy, and those with dubious Australian occurrences, should be prioritized for taxonomic revision and specimen re-examination to clarify their status (Wege et al., 2014). The species assigned possibly extant and possibly extinct should be searched for where possible, with a focus on accurate recording of search effort, and seasonal and habitat condition (Keith, 2000; Silcock et al., 2014). We suggest that taxa assessed as possibly extinct should be retained on lists, or added where necessary, and those that are listed as possibly extant should be removed pending further survey. This treatment would leave 33 taxa as presumed extinct in Australia, albeit with two-thirds ranked as possibly rather than probably extinct. Two-thirds occur in highly modified habitats with well-documented threats, particularly where habitat clearing for agriculture and urbanization coincides with high levels of narrow-range endemism (Burgman et al., 2007). Grazing and hydrological modification seem to have played a part for numerous taxa. The remainder occur in habitats that are not substantially modified, including four that seem to have become extinct in the absence of any known or suspected threat. Extinction is a natural process and the possibility exists that some taxa may have become extinct independent of human activities (Richman et al., 1988; Williamson, 1989), although undoubtedly most extinctions are anthropogenic (Regan et al., 2001; Barnosky et al., 2011).

More than 120 species formerly considered extinct have been rediscovered in Australia since the mid 1970s, many of which eluded detection for more than a century (Supplementary Table 3). This cautions against declaring species extinct, particularly for those that may be ephemeral in response to disturbance (Kirkpatrick \& Gilfedder, 1998; Duretto et al., 2017). Most species listed as Presumed Extinct in Leigh et al. (1984) were known from single or few, low-precision pre-190o records, and were not rediscovered until concerted flora survey and taxonomic studies since the 1970s. Many of these were initially assessed as having a slim chance of being rediscovered, primarily because of severe habitat loss and modification (Leigh et al., 1984). Even species that occur in close proximity to well-collected urban centres can remain undetected for many years, as demonstrated by recent rediscoveries in the Perth and Sydney metropolitan areas (Davis, 2012; Duretto et al., 2017).

Rediscovery of presumed extinct taxa, particularly those that are considered to have always been rare, could be considered parallel to the continuing discovery of new species. Between 1990 and 2009, an estimated mean of $>250$ taxa of flowering plants per annum have been described as new (Chapman, 2009). Some of these are mere formalizations of long-known or suspected informal taxa, but many represent genuine new discoveries. The discovery of a new species is closely akin to the rediscovery of a species known by only one or few historic collections. In this light, we should not be surprised or suspicious of rediscoveries of presumed extinct species.

Our review highlights the differences in assessing flora compared to fauna extinctions (Boyd \& Stanfield, 1998; Collen et al., 2010). Plants often have persistent seedbanks, increasing the effective generation time and making it difficult to confirm extinction on the basis of the species' absence in the above-ground plant community (Silcock et al., 2014). There are usually fewer records for plants, often only the type specimen. This makes it difficult to be confident of taxonomic status, as well as rendering it impossible to infer declines. However, most plant sightings are reinforced by collections, thus removing the issue of assessing the veracity of sightings, which is a vexed issue for inferring animal extinction (Boyd \& Stanfield, 1998; Solow, 2005). The task of assessing extinction likelihood has been made more streamlined by the digitization of many herbarium collections, including the Australian Virtual Herbarium (CHAH, 2016).

Despite our analysis pointing to fewer extinctions than previously thought, there may also be undocumented extinctions, where species disappeared before they were collected. The relatively small number of botanical collectors in Australia prior to broad-scale habitat modification would not have collected a comprehensive sample of the entire vascular flora (Keith \& Burgman, 2004). Undocumented extinctions are especially likely to have occurred in rapidly modified habitats that were not well-surveyed prior to modification, especially those that contain endemic and restricted species, for example Great Artesian Basin springs (Rossini et al., 2018) and the Western Australian Wheatbelt. There are also numerous taxa that are not listed as extinct but have not been seen for many years (Gibson, 2016). Some occur in highly modified habitats, and surveys are urgently required to assess their status.

Even accounting for possible undocumented extinctions, almost 60 times as many taxa are listed as being at risk of global extinction (i.e. Critically Endangered or Endangered under federal and/or state legislation) than have become extinct since 1788 . This could be a result of 
the inherent resilience of the flora, whereby species can become extremely reduced in range and abundance but are able to persist. In some ancient landscapes such as southwestern Australia, long-term landscape stability has resulted in a propensity for flora to occur in small disjunct populations and have genetic systems to cope with this (Byrne \& Hopper, 2008; Hopper et al., 2016). The relative resilience of Australia's flora in comparison to its fauna is highlighted by total extinction rates. Over $10 \%$ of Australia's terrestrial mammals (Woinarski et al., 2015) and 3.5\% of its birds (Szabo et al., 2012) have become extinct in the past 200 years, compared to $0.15 \%$ of its flora.

Alternatively, the discrepancy between the extinct and threatened lists could highlight a looming extinction debt (Vellend et al., 2006; Kolk \& Naaf, 2015; Halley et al., 2017). Under this scenario many plants listed as threatened are functionally extinct, having fallen below the critical number to sustain their populations in the long term, or with populations dominated by mature individuals with minimal recruitment. Of the 660 species listed as Critically Endangered or Endangered at a national level, 62 are known from $<50$ individuals, and 300 from $<250$, well below numbers considered to represent long-term viable populations (Traill et al., 2010). Many of these are now restricted to tiny remnants that are inherently vulnerable to degradation and within which ecological processes, particularly those driving recruitment, no longer operate.

The list and accompanying data presented here provide a baseline for tracking plant extinctions in Australia. The reasons for assigning a species to each extinction likelihood category are explicit, through assembling the best available information on species biology, ecology and search effort, and working each species through the key. This avoids the uncertainties and biases that tend to plague decisions on assigning extinction status (Keith et al., 2017). It will now be clear whether additions or removals from the presumed extinct list are a result of taxonomic revisions, specimen rediscoveries or real changes to status (i.e. documented extinctions or rediscoveries). The use of multiple explicitly evaluated extinction likelihood categories provides a more meaningful measure for reporting on changes over time and between regions than the variable and changeable presumed extinct lists, as they are currently compiled. By accurately evaluating, understanding and acknowledging extinctions, we come closer to preventing more species being added to the list of the lost.

Acknowledgements We acknowledge the many botanists who shared their knowledge of presumed and possibly extinct species, and their efforts to find them, and who delved into herbarium specimens and often murky taxonomies: Greg Keighery, Mike Hislop, Kevin Thiele, Neil Gibson, Barbara Rye, Dave Coates, Sarah Barrett, Barbara Rye, Andrew Webb, Bree Phillips, Anne Harris and Carolyn Wilkins (Western Australia);
Lachlan Copeland, Peter Weston, Bob Makinson, Amanda Jowett, Liz Tasker, Mark Clements, Tony Auld, John Briggs, Steve Douglas, Keith McDougall, Lachlan Willmott (New South Wales); Rigel Jensen, Bob Jago, John Thompson, John Neldner, Bill McDonald, Lui Weber, Bill O’Donnell, Keith McDonald, Paul Forster (Queensland); Bob Bates, Doug Bickerton, Peter Lang, Dan Duval, Greg Guerin (South Australia); Paul Foreman, Jeff Jeanes, Gary Backhouse, Neville Scarlett (Victoria); Richard Schahinger, Jamie Kirkpatrick (Tasmania). Neil Gibson commented on the text and checked Appendices for Western Australia. John Woinarski alerted us to numerous additional species that are or have been considered extinct. This work was funded by the National Environmental Science Program's Threatened Species Recovery Hub. ARF's examination of material in European and US herbaria was supported by an IPID4all Germany Academic Exchange, Technische Universität Dresden Graduate Academy Project 2015_43 and a Queensland Smithsonian Fellowship 2017.

Author contributions Research design, data collation, writing: JLS; discussion of ideas and writing: RJF; data contribution, discussion of ideas and writing: ARF, NGW.

\section{Conflicts of interest None.}

Ethical standards This research abided by the Oryx guidelines on ethical standards.

\section{References}

BAiley, C. (2013) Shadow of the Thylacine: One Man's Epic Search for the Tasmanian Tiger. The Five Mile Press, Scoresby, Australia.

Barnosky, A.D., Matzke, N., Tomiya, S., Wogan, G.O.U., Swartz, B., Quental, T.B. et al. (2011) Has the Earth's sixth mass extinction already arrived? Nature, 471, 51-57.

Bonham, K.J. (1997) Native land snails of King Island and the hunter group. The Tasmanian Naturalist, 119, 10-22.

Boyd, I.L. \& StAnfield, M.P. (1998) Circumstantial evidence for the presence of monk seals in the West Indies. Oryx, 32, 310-316.

BRIgGS, J.D. \& LeIgH, J.H. (1996) Rare or Threatened Australian Plants. 4th edition. CSIRO Publishing, Canberra, Australia.

Burgman, M.A., Keith, D., Hopper, S.D., Widyatmoko, D. \& DRILL, C. (2007) Threat syndromes and conservation of the Australian flora. Biological Conservation, 134, 73-82.

Butchart, S.H.M., Stattersfield, A.J. \& Brooks, T.M. (2006) Going or gone: defining 'possibly extinct' species to give a truer picture of recent extinctions. Bulletin of the British Ornithologists' Club, 126A, 7-24.

Byк, A., Bezdek, A., Gazurek, T., Kral, D. \& Tylkowski, S. (2018) Ahermodontus bischoffi-rediscovery of an endemic dung beetle species (Coleoptera: Scarabaeidae: Aphodiinae) in Albania after more than 80 years. Zootaxa, 4370, 283-288.

Byrne, M. \& Hopper, S.D. (2008) Granite outcrops as ancient islands in old landscapes: evidence from the phylogeography and population genetics of Eucalyptus caesia (Myrtaceae) in Western Australia. Biological Journal of the Linnean Society, 93, 177-188.

CHaH (Council of Heads of Australasian Herbaria) (2016) The Australasian Virtual Herbarium. Http://avh.chah.org.au [accessed December 2016].

Chapman, A.D. (2009) Numbers of Living Species in Australia and the World. 2nd edition. Report for the Australian Biological Resources Study, Canberra, Australia. Https://www.environment.gov.au/ system/files/pages/2ee3f4a1-f130-465b-9c7a-79373680ao67/files/ nlsaw-2nd-complete.pdf [accessed 23 October 2108].

Collar, N.J. (1998) Extinction by assumption; or, the Romeo Error on Cebu. Oryx, 32, 239-244. 
Collen, B., Purvis, A. \& Mace, G.M. (2010) When is a species really extinct? Testing extinction inference from a sighting record to inform conservation assessment. Diversity and Distributions, 16, 755-764.

D Avis, R.W. (2012) Ptilotus christineae is synonymous with the previously presumed extinct taxon P. pyramidatus. Nuytsia, 22, 335 .

de Lírio, E.J., Freitas, J., Negrão, R., Martinelli, G. \& Peixoto, A.L. (2017) A hundred years' tale: rediscovery of Mollinedia stenophylla (Monimiaceae) in the Atlantic rainforest, Brazil. Oryx, 52, 437-441.

Dooley, S. (2013) Out of the shadows. Australian Birdlife, 2, 26-30.

Duretto, M.F., Orme, A., Rodd, J., Stables, M. \& Toelken, H. (2017) Hibbertia fumana (Dilleniaceae), a species presumed to be extinct rediscovered in the Sydney region, Australia. Telopea, 20, $143-146$.

Fitzpatrick, J.W., Lammertink, M., Luneau, M.D., Gallagher, T.W., Harrison, B.R., Sparling, G.M. et al. (2005) Ivory-billed woodpecker (Campephilus principalis) persists in continental North America. Science, 308, 1460-1462.

Gibson, N. (2016) Western Australian plant taxa not collected for more than 50 yeras. Nuytsia, 27, 139-164.

Halley, J.M., Monokrousos, N., Mazaris, A.D. \& Vokou, D. (2017) Extinction debt in plant communities: where are we now? Journal of Vegetation Science, 28, 459-461.

Office of Environment \& Heritage (2017) Nielsen Park Sheoak-Profile. New South Wales Government, Sydney, Australia. Http://www.environment.nsw.gov.au/threatenedspeciesapp/profile. aspx?id=10039 [accessed 27 March 2018].

Hopper, S.D., Silveira, F.A.O. \& Fiedler, P.L. (2016) Biodiversity hotspots and Ocbil theory. Plant and Soil, 403, 167-216.

IUCN (2012) IUCN Red List categories. Version 3.1. 2nd edition. IUCN Species Survival Commission. World Conservation Union, Gland, Switzerland and Cambridge, UK.

IUCN Standards and Petitions Subcommittee (2017) Guidelines for Using the IUCN Red List Categories and Criteria. Version 13. Prepared by the Standards and Petitions Subcommittee. Http://www.iucnredlist.org/documents/RedListGuidelines.pdf [accessed 13 July 2018].

KeIth, D.A. (2000) Sampling designs, field techniques and analytical methods for systematic plant population surveys. Ecological Management and Restoration, 1, 125-139.

Keith, D.A. \& Burgman, M.A. (2004) The Lazarus effect: can the dynamics of extinct species lists tell us anything about the status of biodiversity? Biological Conservation, 117, 41-48.

Keith, D.A., Butchart, S.H.M., Regan, H.M., Harrison, I., Akcakaya, H.R., Solow, A.R. \& Burgman, M.A. (2017) Inferring extinctions I: a structured method using information on threats. Biological Conservation, 214, 320-327.

KiRKPATRICK, J.B. \& GilfEDdER, L. (1998) Conserving weedy natives: two Tasmanian endangered herbs in the Brassicaceae. Australian Journal of Ecology, 23, 466-473.

Kolk, J. \& NAAF, T. (2015) Herb layer extinction debt in highly fragmented temperate forests-completely paid after 160 years? Biological Conservation, 182, 164-172.

Koopowitz, H. \& Kaye, H. (eds) (1990) Plant Extinction: a Global Crisis. Christopher Helm, London, UK.

Leigh, J.H., Boden, R. \& Briggs, J. (1984) Extinct and Endangered Plants of Australia. The Macmillan Company of Australia, South Melbourne, Australia.

Leigh, J.H., Briggs, J. \& Hartley, W. (1981) Rare or Threatened Australian Plants. Australian National Parks and Wildlife Service, Canberra, Australia.
Lindenmayer, D.B. (2007) On Borrowed Time: Australia's Environmental Crisis and What We Must Do About It. CSIRO Publishing, Camberwell, Australia.

Mace, G.M., Collar, N.J., Gaston, K.J., Hilton-Taylor, C., Akcakaya, H.R., Leader-Williams, N. et al. (2008) Quantification of extinction risk: IUCN's system for classifying threatened species. Conservation Biology, 22, 1424-1442.

Nipperess, D.A. (2015) A separate creation: diversity, distinctiveness and conservation of Australian wildlife. In Austral Ark: The State of Wildlife in Australia and New Zealand (eds A. Stow, N. Maclean \& G.I. Holwell), pp. 1-23. Cambridge University Press, Cambridge, UK.

Pimm, S.L., Jenkins, C.N., Abell, R., Brooks, T.M., Gittleman, Joppa, L.N. et al. (2014) The biodiversity of species and their rates of extinction, distribution, and protection. Science, 344, 1246752.

Purvis, A., Jones, K.E. \& Mace, G.M. (200o) Extinction. Bioessays, 22, 1123-1133.

REED, J.M. (1996) Using statistical probability to increase confidence of inferring extinction. Conservation Biology, 10, 1283-1285.

Regan, H.M., Lupia, R., Drinnan, A.N. \& Burgman, M.A. (2001) The currency and tempo of extinction. American Naturalist, 157, $1-10$.

Richman, A., Case, T.J. \& Schwaner, T.D. (1988) Natural and unnatural extinction rates of reptiles on islands. The American Naturalist, 131, 611-630.

Rossini, R.A., Fensham, R.J., Stewart-Koster, B., Gotch, T. \& Kennard, M. (2018) Biogeographical patterns of endemic diversity and its conservation in Australia's artesian desert springs. Diversity and Distributions, 24, 1199-2016.

Ryan, J.C. (2009) Why do extinctions matter? Mourning the loss of indigenous flora in the southwest of Western Australia. Philament, $15,1-30$.

SCHRIRE, B. (2007) Going. . . going. . . is it gone? Streblorrhiza speciosa the Phillip Island glory pea. Curtis's Botanical Magazine, 24, 196-197.

Scotт, J.K. \& YeOH, P.B. (1995) The rediscovery and distribution of Rumex drummondii (Polygonaceae), in south-western Australia. Australian Journal of Botany, 43, 397-405.

Silcock, J.L., Healy, A.J. \& Fensham, R.J. (2014) Lost in time and space: re-assessment of conservation status in an arid-zone flora through targeted field survey. Australian Journal of Botany, 62, $674-688$.

Sochor, M., Egertova, Z., Hrones, M. \& Dancak, M. (2018) Rediscovery of Thismia neptunis (Thismiaceae) after 151 years. Phytotaxa, 340, 71-78.

Solow, A.R. (2005) Inferring extinction from a sighting record. Mathematical Biosciences, 195, 47-55.

Szabo, J.K., Khwaja, N., Garnett, S.T. \& Butchart, S.H. (2012) Global patterns and drivers of avian extinctions at the species and subspecies level. PLOS ONE, 7, e47080.

Thackway, R. \& Cresswell, I.D. (1995) An Interim Biogeographic Regionalisation for Australia: a Framework for Setting Priorities in the National Reserve System Cooperative Program. Version 4.o. Australian Nature Conservation Agency, Canberra, Australia.

Thompson, C.J., Koshina, V., Burgman, M.A., Butchart, S.H.M. \& STONE, L. (2017) Inferring extinctions II: a practical, iterative model based on records and surveys. Biological Conservation, 214, 328-335.

Traill, L.W., Brook, B.W., Frankham, R.R. \& Bradshaw, C.J.A. (2010) Pragmatic population viability targets in a rapidly changing world. Biological Conservation, 143, 28-34.

Vellend, M., Verheyen, K., Jacquemyn, H., Kolb, A., Van Calster, H., Peterken, G. \& Hermy, M. (2006) Extinction debt of forest plants persists for more than a century following habitat fragmentation. Ecology, 87, 542-548. 
Wapstra, M., Duncan, F., Buchanan, A. \& Schahinger, R. (2006) Finding a botanical Lazarus: tales of Tasmanian plant species 'risen from the dead'. The Tasmanian Naturalist, 128, 61-85.

Wege, J.A., Thiele, K.R., Shephard, K.A., Butcher, R., Macfarlane, T.D. \& Coates, D.J. (2014) Strategic taxonomy in a biodiverse landscape: a novel approach to maximizing conservation outcomes for rare and poorly known flora. Biodiversity and Conservation, 24, 17-32.
Williamson, M. (1989) Natural extinction on islands. Philosophical Transactions of the Royal Society B, 325, 457-468.

Woinarsi, J.C.Z., Burbidge, A.A. \& Harrison, P.L. (2015)

Ongoing unravelling of a continental fauna: decline and extinction of Australian mammals since European settlement. Proceedings of the National Academy of Sciences of the United States of America, 112, 4531-4540. 